The Journal of Bone E Joint Surgery
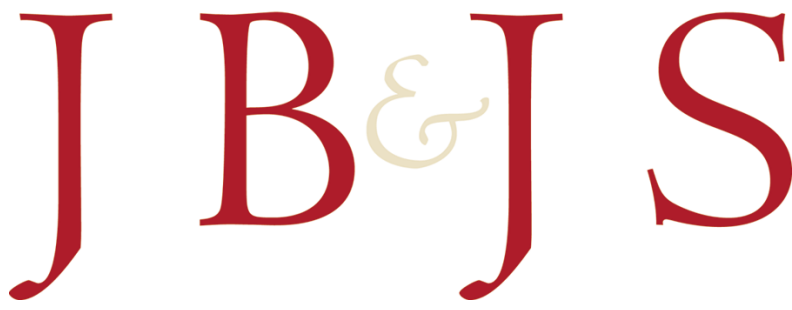

This is an enhanced PDF from The Journal of Bone and Joint Surgery

The PDF of the article you requested follows this cover page.

\title{
Biologic Characteristics of Fibrous Hamartoma from Congenital Pseudarthrosis of the Tibia Associated with Neurofibromatosis Type 1
}

Tae-Joon Cho, Joong-Bae Seo, Hye Ran Lee, Won Joon Yoo, Chin Youb Chung and In Ho Choi J Bone Joint Surg Am. 2008;90:2735-2744. doi:10.2106/JBJS.H.00014

This information is current as of December 23, 2009

Reprints and Permissions

Publisher Information
Click here to order reprints or request permission to use material from this article, or locate the article citation on jbjs.org and click on the [Reprints and Permissions] link.

The Journal of Bone and Joint Surgery

20 Pickering Street, Needham, MA 02492-3157

www.jbjs.org 


\title{
Biologic Characteristics of Fibrous Hamartoma from Congenital Pseudarthrosis of the Tibia Associated with Neurofibromatosis Type 1
}

\author{
By Tae-Joon Cho, MD, Joong-Bae Seo, MD, Hye Ran Lee, MS, Won Joon Yoo, MD, Chin Youb Chung, MD, and In Ho Choi, MD
}

Investigation performed at the Department of Orthopaedic Surgery, Seoul National University Children's Hospital, Seoul, South Korea

\begin{abstract}
Background: Fibrous hamartoma is a key pathologic component of congenital pseudarthrosis of the tibia, a challenging and disabling bone disorder. We investigated the biologic characteristics of fibrous hamartoma cells in order to better understand the pathogenesis of this rare disease.
\end{abstract}

Methods: Fibrous hamartoma tissues were surgically excised at the time of osteosynthesis from seven patients with congenital pseudarthrosis of the tibia associated with neurofibromatosis type 1. Distal tibial periosteum was also harvested as control tissue during tibial derotation osteotomy from two other patients with cerebral palsy and one patient with idiopathic internal tibial torsion. Fibroblast-like cells were enzymatically dissociated and cultured from these tissues. Immunophenotypes were investigated for positive (CD44 and CD105) and negative (CD45 and CD14) mesenchymal lineage cell markers, and the mRNA expressions of bone morphogenetic protein(BMP)-2, BMP-4, and their receptors were assayed by reverse transcription-polymerase chain reaction. After rhBMP-2 treatment, the changes in alkaline phosphatase activity, and in the mRNA expressions of type-I collagen (COL1A1), alkaline phosphatase, and osteocalcin genes, were assayed with use of an RNase protection assay. The mRNA expressions of receptor activator of nuclear factorkappa B ligand (RANKL) and osteoprotegerin (OPG) were quantitatively assayed with use of real-time RT-PCR. Osteoclastic differentiation of $\mathrm{RAW}_{264.7}$ cells in coculture with fibrous hamartoma cells was evaluated.

Results: All fibrous hamartoma and tibial periosteal cells tested were CD44+/CD105+/CD45-/CD14- and expressed the mRNAs of BMP-2, BMP-4, and their receptors. The baseline mRNA expressions of COL1A1, alkaline phosphatase, and osteocalcin genes in the fibrous hamartoma cells were diverse. These gene expressions were upregulated by BMP treatment in tibial periosteal cells but did not change or were downregulated in fibrous hamartoma cells. Fibrous hamartoma cells expressed higher levels of RANKL and lower levels of OPG than did tibial periosteal cells. Coculture with fibrous hamartoma cells enhanced osteoclastic differentiation of $\mathrm{RAW}_{264.7}$ cells.

Conclusions: Fibrous hamartoma cells maintain some of the mesenchymal lineage cell phenotypes, but do not undergo osteoblastic differentiation in response to BMP. They are more osteoclastogenic than are tibial periosteal cells.

Clinical Relevance: The low osteogenicity and high osteoclastogenicity of fibrous hamartoma cells may play a role in the pathogenesis of congenital pseudarthrosis of the tibia. This should be taken into consideration when developing a treatment protocol for congenital pseudarthrosis of the tibia.

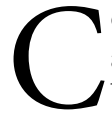
ongenital pseudarthrosis of the tibia usually presents as a congenitally dysplastic tibia with anterolateral bowing, cystic lesion, sclerotic change, and/or diaphyseal narrowing, which fractures spontaneously or after minor trauma and then establishes a pseudarthrosis if treated conservatively ${ }^{1}$. Although surgical intervention has achieved substantial improvements in terms of the healing rates of congenital pseudarthrosis of the tibia over recent decades, challenging problems still jeopardize the function of the affected $\operatorname{limb}^{2}$.

Disclosure: In support of their research for or preparation of this work, one or more of the authors received, in any one year, outside funding or grants in excess of \$10,000 from Seoul National University Hospital (SNUH-04-2007-039 and SNUH-04-2007-081). Neither they nor a member of their immediate families received payments or other benefits or a commitment or agreement to provide such benefits from a commercial entity. No commercial entity paid or directed, or agreed to pay or direct, any benefits to any research fund, foundation, division, center, clinical practice, or other charitable or nonprofit organization with which the authors, or a member of their immediate families, are affiliated or associated. 

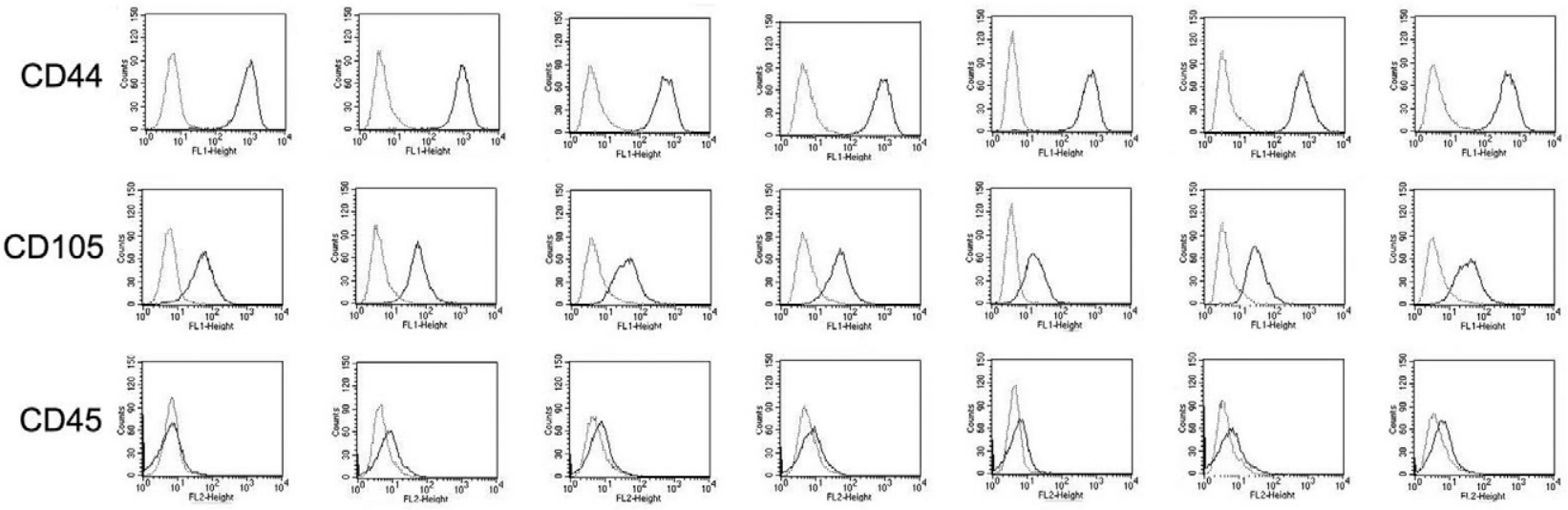

CD14
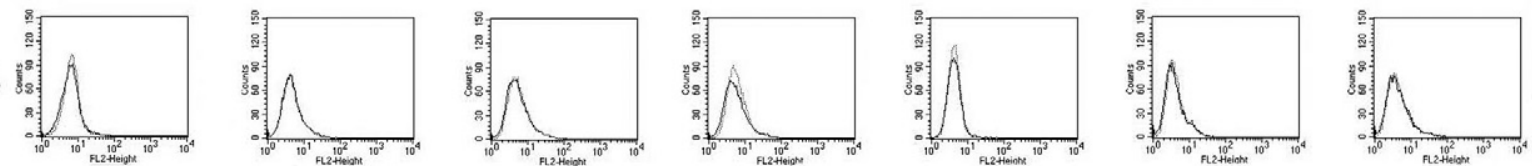

TP2

$\mathrm{FH} 1$

$\mathrm{FH} 3$

$\mathrm{FH} 4$

$\mathrm{FH} 5$

$\mathrm{FH} 7$

Fig. 1-A

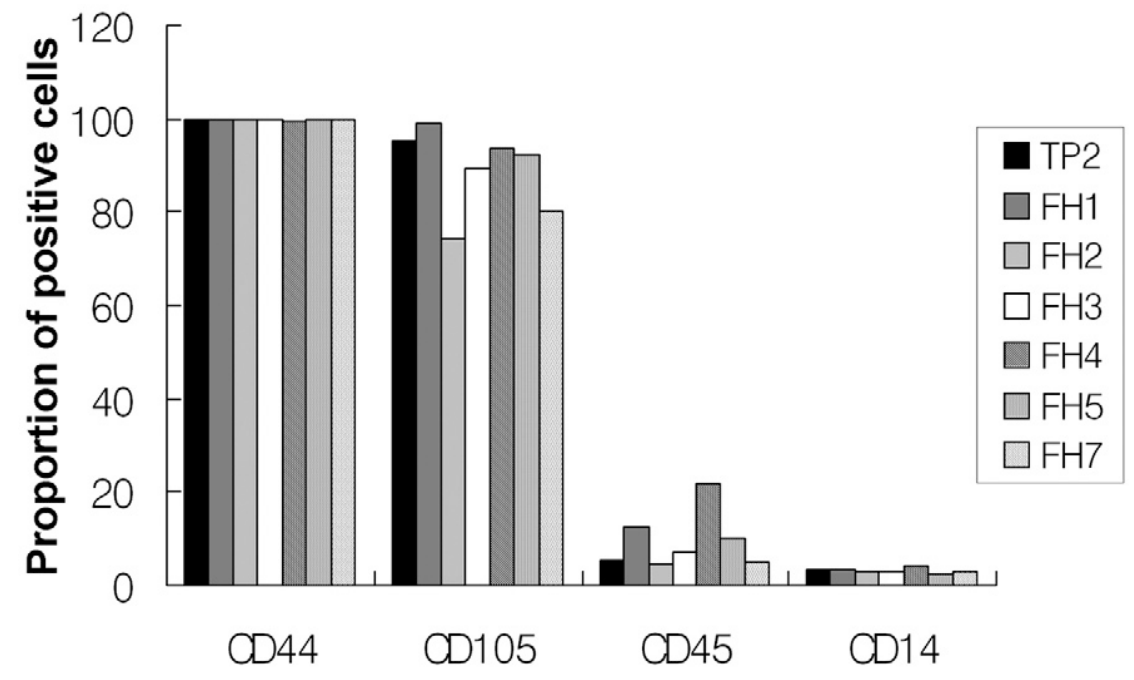

Fig. 1-B

Figs. 1-A, 1-B, and 1-C Flow cytometric analysis of tibial periosteum (TP) and fibrous hamartoma (FH) cells. Fig. 1-A Histograms representing the number of cells (y axis) against the fluorescence intensity ( $x$ axis, log scale). Gates were set on $97 \%$ of the antibody-unlabeled data. Fig. 1-B Proportions of cells positive for the surface markers. Tibial periosteal and fibrous hamartoma cells tested were positive for CD44 and CD105 and were negative for CD45 and CD14.

Fibrous hamartoma is fibromatosis-like tissue at the pseudarthrosis site, which is continuous with abnormally thickened periosteum in adjacent bone segments, and has long been regarded as the key pathology of congenital pseudarthrosis of the tibia ${ }^{3}$. An ultrastructural study found that the vast majority of cells in fibrous hamartoma were fibroblasts lacking a basement membrane in the stationary phase ${ }^{4}$. A more recent histochemical and immunohistochemical study revealed that fibrous hamartoma was composed of an undifferentiated type of membranous tissue having the potential to differentiate into several lines of mesenchymally derived tissues $^{5}$. On the other hand, impaired blood circulation by the constricting fibrous hamartoma ${ }^{6}$ or by the accumulation of nerve cells surrounding small arteries ${ }^{7}$ was also suggested as a pathogenic mechanism of congenital pseudarthrosis of the tibia. However, the cells composing fibrous hamartoma have not been fully characterized in terms of osteogenicity and osteoclastogenic potential.

Congenital pseudarthrosis of the tibia is frequently associated with neurofibromatosis type 1 (NF1), which in patients with congenital pseudarthrosis of the tibia has been reported to have a prevalence ranging from $40 \%$ to $80 \%{ }^{6}$, although only $1 \%$ to $4 \%$ of patients with neurofibromatosis type 1 have congenital pseudarthrosis of the tibia develop ${ }^{8}$. Neurofibromatosis 


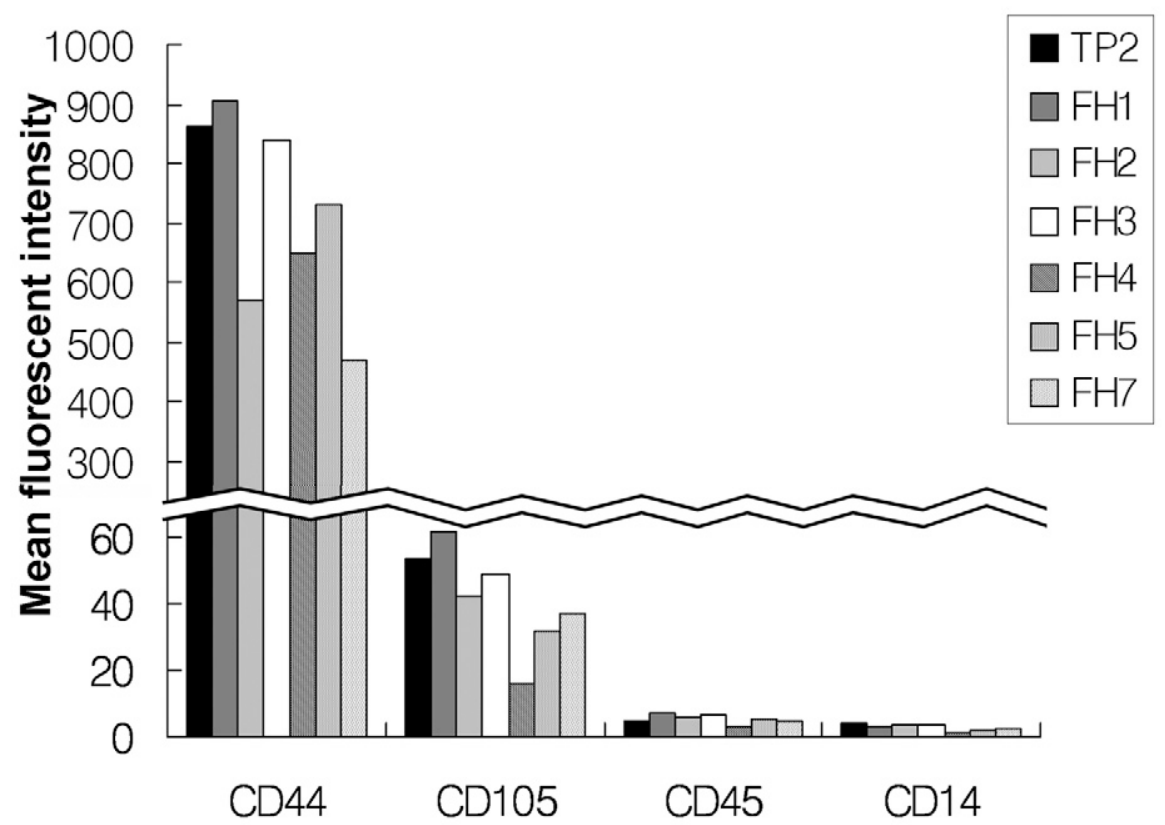

Fig. 1-C

Mean fluorescent intensities of the surface markers. All cells tested showed stronger intensity for CD44 than CD105 but were negligible for CD45 and CD14.

type 1 is caused by mutation in the $N f 1$ gene, which encodes neurofibromin ${ }^{9}$. As it converts active Ras-GTP into inactive Ras-GDP, neurofibromin negatively regulates Ras activity ${ }^{10}$. $N f 1$ is expressed in many types of cells, including maturing chondrocytes, hypertrophic chondrocytes, osteoblasts, osteocytes, and osteoclasts ${ }^{11}$. Furthermore, its expression has been reported at fracture sites in a mouse model and at pseudar- throsis sites in a rat model ${ }^{12}$, suggesting the involvement of mutant $N f 1$ in the development of pseudarthrosis.

Loss of neurofibromin function and the subsequent deregulation of Ras-MAPK activity may impair osteoblast differentiation. Alkaline phosphatase staining and mRNA expressions of osteocalcin and osteonectin are decreased in mesenchymal stem cell-progenitor cells from $N f 1 \pm$ mice, which could

\section{TABLE I Patient Data and the Experiments in Which Each Cell Preparation Was Used*}

\begin{tabular}{|c|c|c|c|c|c|c|c|c|c|c|}
\hline \multirow[b]{2}{*}{ Label } & \multirow[b]{2}{*}{ Age (yr) } & \multirow[b]{2}{*}{ Sex } & \multirow[b]{2}{*}{ Diagnosis } & \multirow[b]{2}{*}{ Tissue } & \multirow[b]{2}{*}{ FACS } & \multirow{2}{*}{$\begin{array}{l}\text { Expression } \\
\text { of BMPs } \\
\text { and Their } \\
\text { Receptors }\end{array}$} & \multirow{2}{*}{$\begin{array}{l}\text { RANKL-OPG } \\
\text { Expression }\end{array}$} & \multirow{2}{*}{$\begin{array}{c}\text { Coculture } \\
\text { with RAW } 264.7 \\
\text { Cells }\end{array}$} & \multicolumn{2}{|c|}{ BMP Treatment } \\
\hline & & & & & & & & & ALP Activity & RPA \\
\hline $\mathrm{FH} 1$ & 6.9 & M & CPT with NF1 & Fibrous hamartoma & $x$ & $x$ & $x$ & & $x$ & $\mathrm{x}$ \\
\hline $\mathrm{FH} 2$ & 3.7 & $\mathrm{~F}$ & CPT with NF1 & Fibrous hamartoma & $x$ & $\mathrm{x}$ & & $\mathrm{x}$ & $x$ & $\mathrm{x}$ \\
\hline FH3 & 4.0 & $\mathrm{~F}$ & CPT with NF1 & Fibrous hamartoma & $x$ & $x$ & $x$ & $x$ & $x$ & $x$ \\
\hline FH5 & 9.2 & M & CPT with NF1 & Fibrous hamartoma & $x$ & $x$ & & $x$ & $x$ & \\
\hline FH6 & 4.3 & $\mathrm{~F}$ & CPT with NF1 & Fibrous hamartoma & & & $\mathrm{x}$ & & & \\
\hline $\mathrm{FH} 7$ & 6.9 & $\mathrm{~F}$ & CPT with NF1 & Fibrous hamartoma & $x$ & & & $x$ & & \\
\hline TP1 & 6.7 & $M$ & Cerebral palsy & Tibial periosteum & & $\mathrm{x}$ & $x$ & & $x$ & $\mathrm{x}$ \\
\hline TP2 & 8.0 & $\mathrm{~F}$ & Cerebral palsy & Tibial periosteum & $x$ & & $X$ & $x$ & & \\
\hline
\end{tabular}

$* \mathrm{FH}=$ fibrous hamartoma, $\mathrm{TP}=$ tibial periosteum, $\mathrm{CPT}=$ congenital pseudarthrosis of the tibia, NF1 = neurofibromatosis type 1, ALP $=$ alkaline phosphatase, RPA = RNase protection assay, FACS = fluorescence-activated cell sorting, RANKL = receptor activator of nuclear factor-kappa B ligand, $\mathrm{OPG}=$ osteoprotegerin, and ITT = idiopathic internal tibial torsion. 

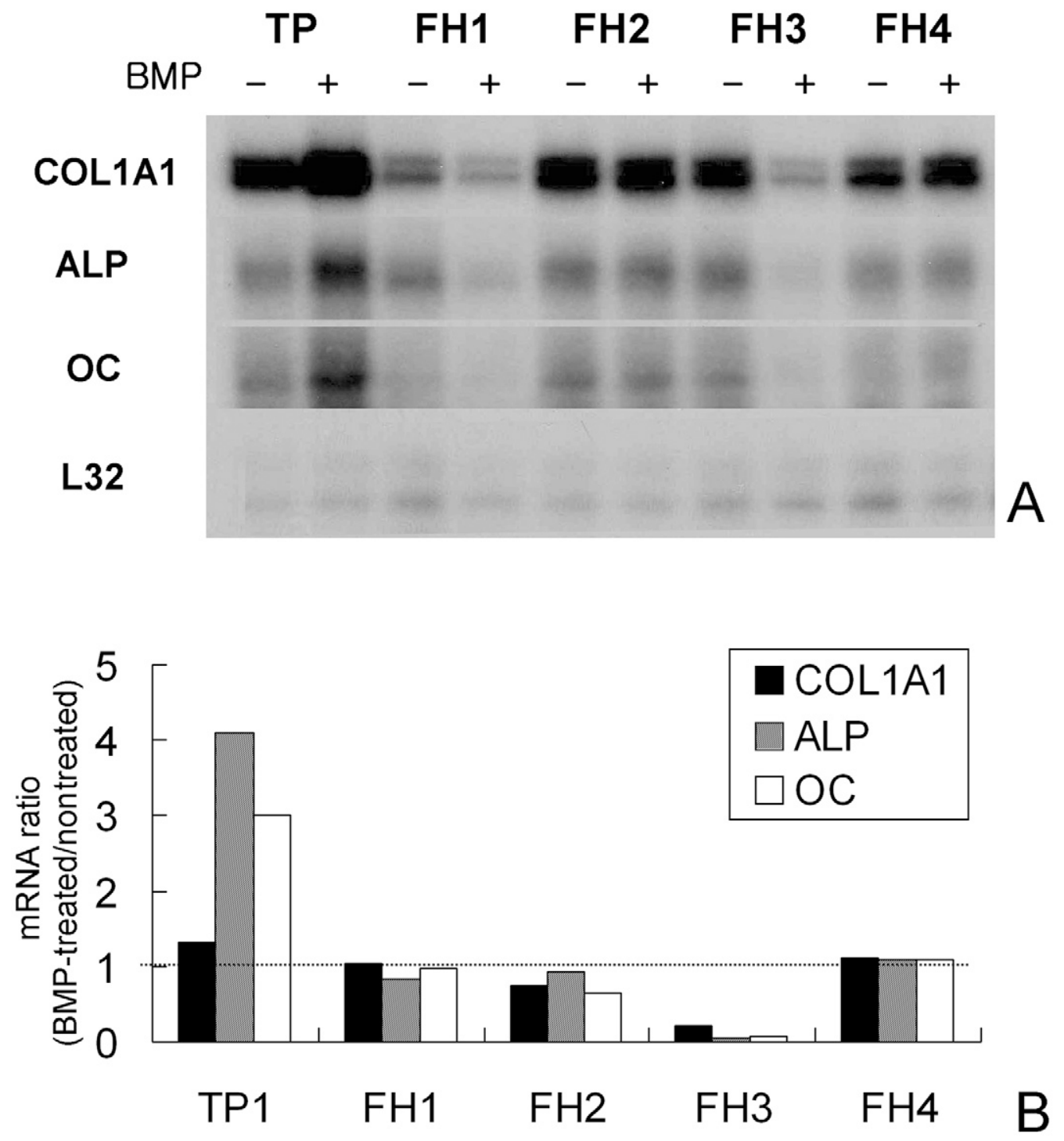

Fig. 2

Figs. 2-A and 2-B Effect of rhBMP-2 treatment on the mRNA expression of COL1A1, alkaline phosphatase (ALP), and osteocalcin (OC) genes. Fig. 2-A An RNase protection assay was performed to compare BMP-treated and nontreated cells. Fig. 2-B Band intensities were normalized against that of L32 (a ribosomal protein used as a "housekeeping" gene). BMP treatment upregulated the expressions of these mRNAs in tibial periosteal (TP) cells, whereas it did not change or even downregulated in fibrous hamartoma $(\mathrm{FH})$ cells.

be restored by the reexpression of the NF1 functional domain ${ }^{13}$. Moreover, the committed osteoprogenitors from $\mathrm{Nfl} \pm$ mice exhibited premature apoptosis and higher proliferation, as well as less osteoblastic differentiation ${ }^{14}$. Increased osteoclastic activity has been well described at cortical bone surfaces in contact with fibrous hamartoma ${ }^{3}$, and this may be another mechanism of the development and recurrence of pseudarthrosis. Nf1 haploinsufficiency was found to sensitize osteoclast precursor cells, activate osteoclasts, and help them to survive ${ }^{15,16}$.

In the current study, we investigated the biologic behavior of fibrous hamartoma cells, the key constituent of congenital pseudarthrosis of the tibia, in order to better understand the pathogenesis of congenital pseudarthrosis of the tibia, addressing the following questions: (1) What is the phenotype of fibrous hamartoma cells? (2) Do fibrous hamartoma cells differentiate into osteoblasts in response to bone morphogenetic protein signaling? (3) Do fibrous hamartoma cells differentiate osteoclast precursors into osteoclasts or activate osteoclasts?

\section{Materials and Methods Primary Cell Culture}

This study was approved by the institutional review board of I Seoul National University Hospital. Human tissues were harvested and used in experiments with informed consent. Fibrous hamartoma tissue was harvested from seven patients 

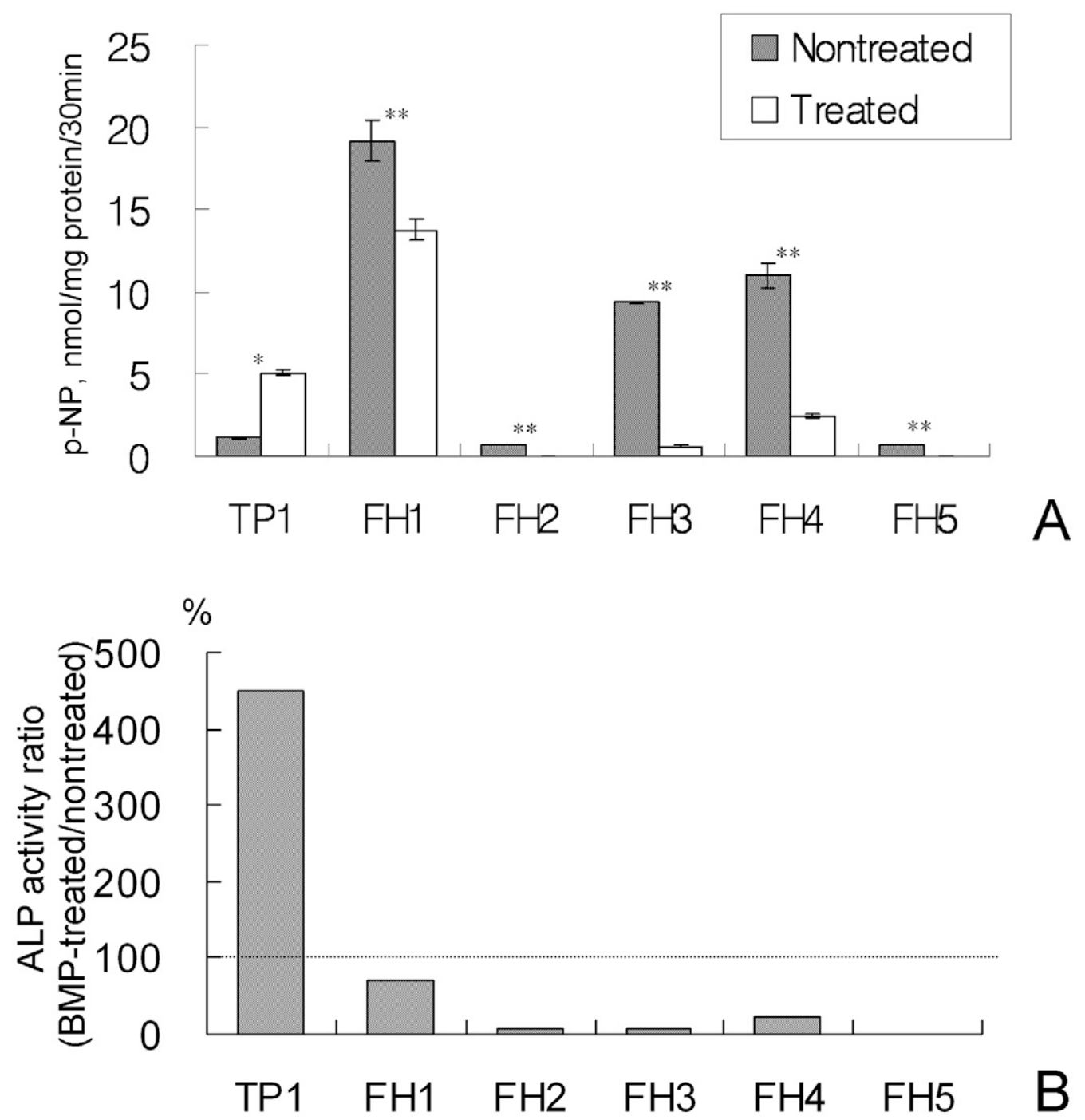

Fig. 3

Figs. 3-A and 3-B Effect of rhBMP-2 on alkaline phosphatase (ALP) activity. Fig. 3-A BMP treatment increased alkaline phosphatase activity in TP1 (tibial periosteal) cells, but decreased it in all fibrous hamartoma (FH) cells tested. The error bars indicate the standard deviation. *The difference between nontreated and BMP-treated cells was significant $(\mathrm{p}<0.05)$. ${ }^{*} \mathrm{p}<0.01$ (Mann-Whitney test). $\mathrm{p}$-NP $=\mathrm{p}$-nitrophenol. Fig. 3-B Data are presented as percentage changes of alkaline phosphatase activity in BMP-treated cells compared with nontreated cells.

with an atrophic type of congenital pseudarthrosis of the tibia associated with NF1, during surgical procedures of osteosynthesis. Distal tibial periosteum was harvested during supramalleolar tibial derotation osteotomy as a normal control from two patients with spastic diplegic cerebral palsy and one patient with idiopathic internal tibial torsion. Fibroblast-like cells were enzymatically dissociated from these tissues and were plated on a 100-mm dish and cultured in Dulbecco's modified Eagle medium (DMEM) containing 10\% fetal bovine serum and antibiotics at $37^{\circ} \mathrm{C}$ in $5 \% \mathrm{CO}_{2}$. When the second passage cells reached confluence, they were trypsinized, frozen, and stored in liquid nitrogen until required. The cells from each patient were denoted by the labels listed in Table I as FH1 through FH7 and TP1 through TP3. As the amount of tissue harvested from the patients was limited, not all tissues were used in all experiments (Table I).

\section{Fluorescence-Activated Cell Sorting Analysis}

Immunophenotypes of fibrous hamartoma and tibial periosteal cells were analyzed by fluorescence-activated cell sorting (FACS). CD44 (matrix receptor) and CD105 (transforming growth factor$\alpha$ [TGF- $\alpha$ ] coreceptor) were used as positive mesenchymal lineage cell markers, and CD45 and CD14 (hematopoietic lineage markers) were used as negative markers ${ }^{17,18}$. Cells $\left(5 \times 10^{5}\right)$ from each specimen were incubated with rat anti-human CD44 monoclonal antibody (eBioscience, San Diego, California) and mouse anti-human CD45 antibody (DakoCytomation, Glostrup, Denmark). Another $5 \times 10^{5}$ cells from each specimen were incu- 
The Journal of Bone \& Joint Surgery $\cdot$ Jbjs.org Volume $90-\mathrm{A} \cdot$ Number $12 \cdot$ December 2008

Biologic Characteristics of Fibrous Hamartoma from Congenital Pseudarthrosis of the Tibia

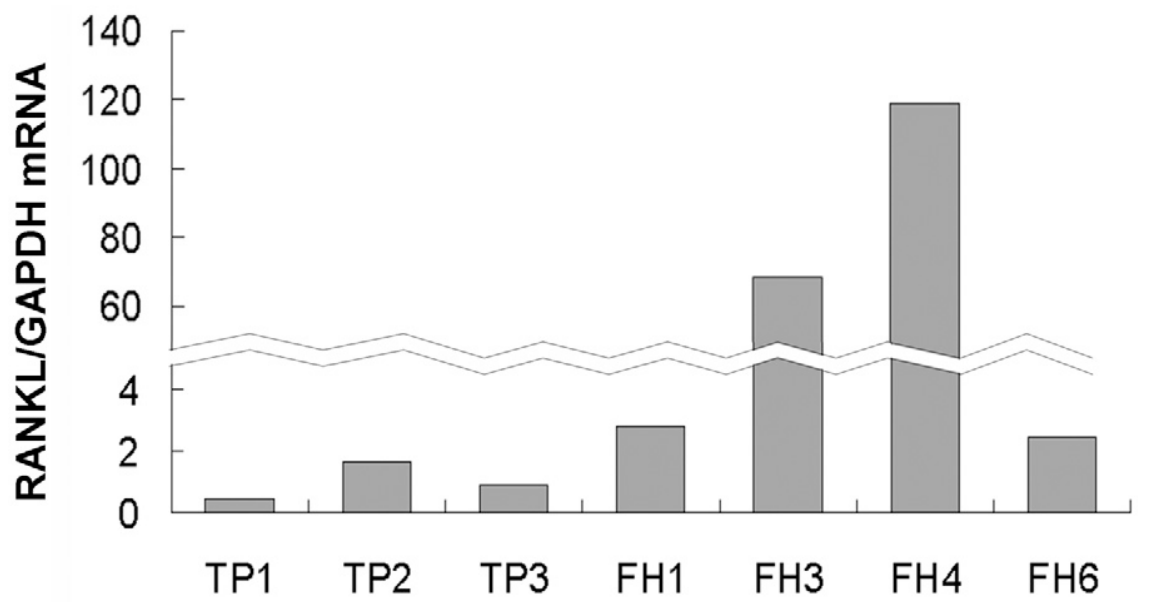

Fig. 4-A

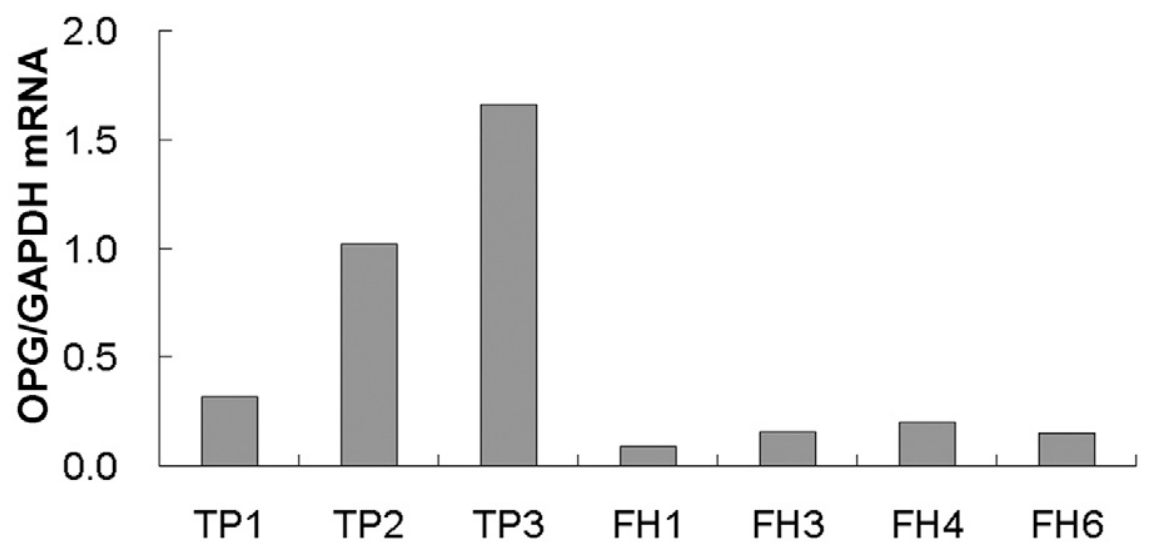

Fig. 4-B

The estimated mRNA levels of RANKL (receptor activator of nuclear factor-kappa B ligand) (Fig. 4-A) and OPG (osteoprotegerin) (Fig. 4-B) in tibial periosteal (TP) and fibrous hamartoma (FH) cells as determined by quantitative real-time RT-PCR. The mRNA level was estimated from the threshold cycle value and was standardized by that of GAPDH. The mean value in tibial periosteal cells was set at 1.0 in this graph. Fibrous hamartoma cells showed higher RANKL mRNA levels and lower OPG mRNA levels than did tibial periosteal cells.

bated with mouse anti-human CD105 antibody (AbD Serotec, Raleigh, North Carolina) and mouse anti-human CD14 antibody (DakoCytomation). Cells incubated with human immunoglobulin $\mathrm{G} 1\left(\mathrm{IgG}_{1}\right)$ were used as negative controls. Cells were analyzed with use of a FACStar flow cytometer (for at least 10,000 events) and CellQuest software (both products were from Becton Dickinson, Oxford, United Kingdom).

\section{RNA Assays}

Total RNA was extracted from plated cells with use of a Trizol reagent (Invitrogen, Carlsbad, California). The mRNA expressions of two bone morphogenetic proteins (BMP-2 and BMP-4) and bone morphogenetic protein receptor types $1 \mathrm{~A}, 1 \mathrm{~B}$, and 2 (BMPR1A, BMPR1B, and BMPR2) were assayed by reverse transcription-polymerase chain reaction (RT-PCR), in order to investigate whether these cells have endogenous osteoblastogenic signals and receptors for them. Glyceraldehyde-3-phosphate dehydrogenase (GAPDH) was used as an internal control.
The mRNA levels of receptor activator of nuclear factorkappa B ligand (RANKL) and osteoprotegerin (OPG) were quantitatively analyzed by real-time RT-PCR. After reverse transcription with use of the SuperScript First-Strand Synthesis System for RT-PCR (Invitrogen), real-time PCR was performed in TaqMan Universal PCR Master Mix (Applied Biosystems, Foster City, California) with use of an ABI Prism 7000 Sequence Detection System (Applied Biosystems). To compare the different gene expression levels, threshold cycle values were compared for relative gene expression analysis. All samples were amplified three times, and mean values were used in calculations. The expression levels of target genes were presented as a ratio of the gene expression to GAPDH mRNA expression.

Human genes encoding COL1A1 (type-I collagen), alkaline phosphatase, and osteocalcin were subcloned from the RT-PCR product with use of the pGEM-T Easy Vector System (Promega, Madison, Wisconsin). An RNase protection assay 

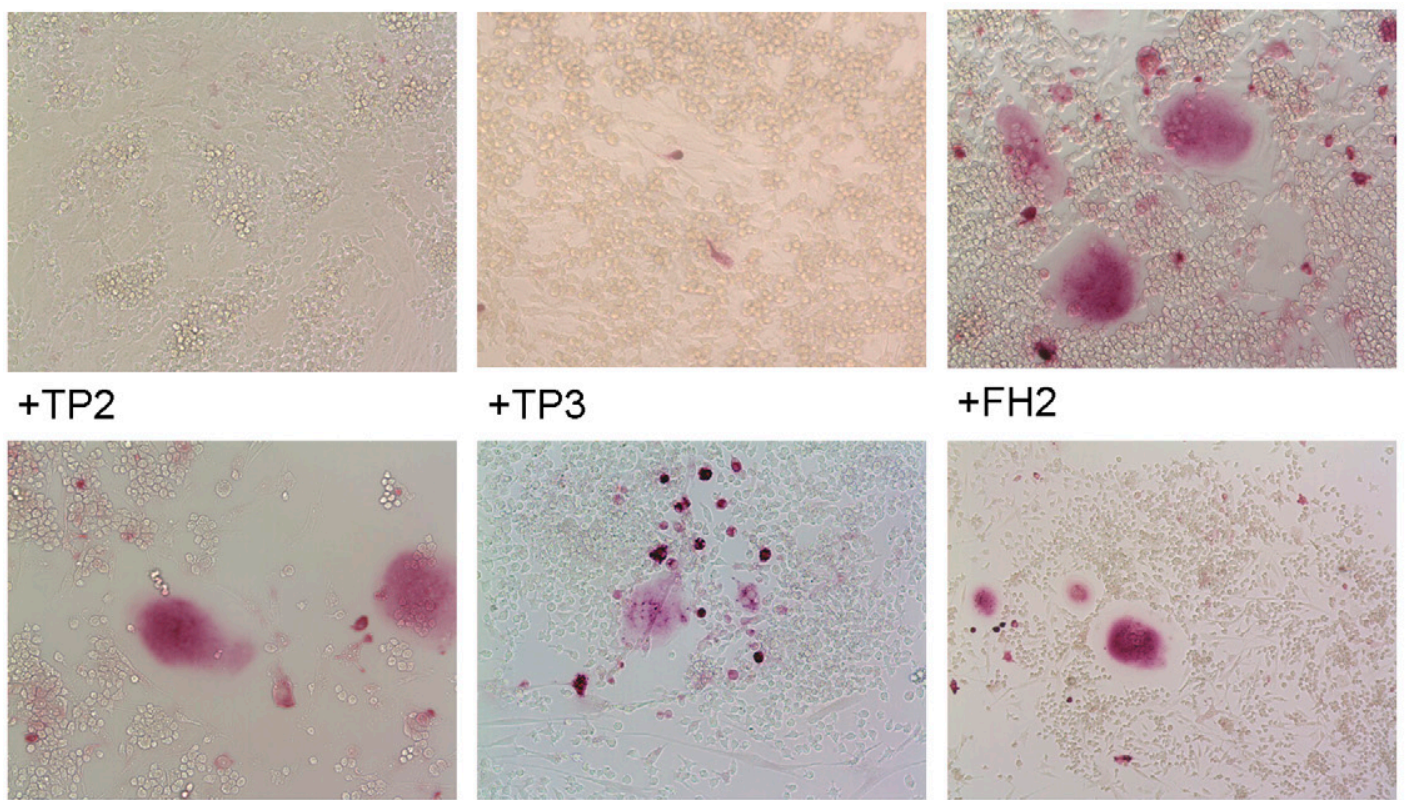

+ TP3

$+\mathrm{FH} 2$

$+\mathrm{FH} 3$

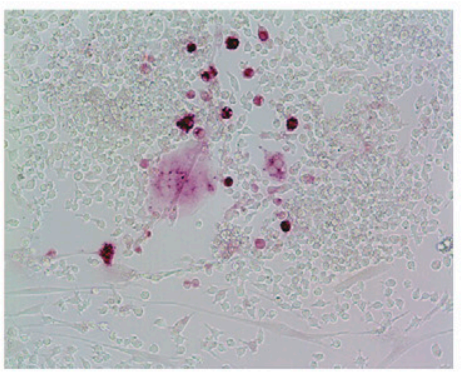

$+\mathrm{FH} 5$

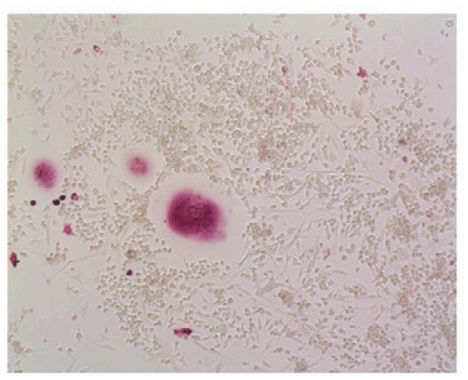

$+\mathrm{FH} 7$

A

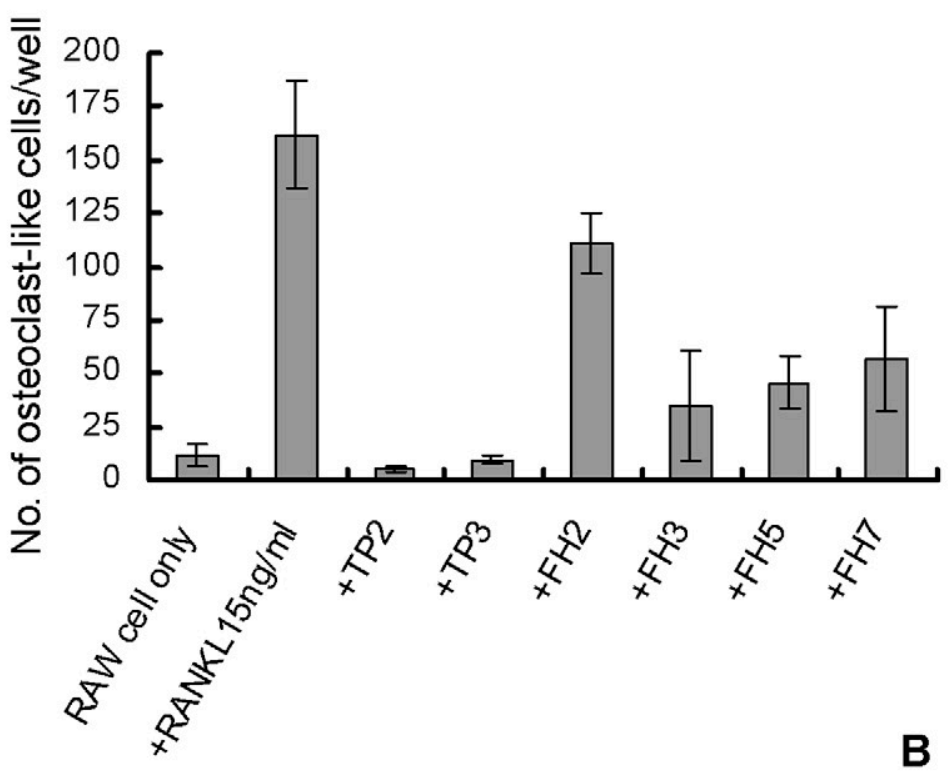

Fig. 5

Figs. 5-A and 5-B Differentiation of RAW 264.7 cells into osteoclast-like cells by coculture with fibrous hamartoma (FH) cells. Fig. 5-A Coculture with TP2 and TP3 (tibial periosteal) cells produced less osteoclast-like cells. Cocultures with fibrous hamartoma cells produced many TRAP (tartrate-resistant acid phosphatase)-positive, multinuclear cells ( $\times 200)$. Fig. 5-B The numbers of osteoclast-like cells formed during coculture with fibrous hamartoma cells were significantly higher than those with tibial periosteal (TP) cells $(p<0.01$, Mann-Whitney test). RANKL $=$ receptor activator of nuclear factor-kappa B ligand.

was performed as previously described ${ }^{19}$. Total RNA was extracted from the cells grown in osteogenic media (DMEM containing $10 \%$ fetal bovine serum, $100 \mathrm{nM}$ dexamethasone, $10 \mathrm{mM}$ sodium glycerophosphate, and $0.05 \mathrm{mM}$ ascorbic acid2-phosphate) with 0 or $100 \mathrm{ng} / \mathrm{mL}$ rhBMP-2 (R and D Systems, Minneapolis, Minnesota) for two weeks. ${ }^{32}$ P-labeled cRNA probes were generated, with use of RNA transcription kits (Pharmingen, San Diego, California), hybridized with 10 $\mu \mathrm{g}$ of total RNA, and then digested with RNase with use of RiboQuant ribonuclease protection kits (Pharmingen). Protected segments of cRNA probes were fractionated by denaturing polyacrylamide gel electrophoresis (PAGE). Specific bands formed by each cRNA probe were quantified and normalized against L32 (a "housekeeping" gene). 
The Journal of Bone \& Joint Surgery - Jbjs.org Volume $90-\mathrm{A} \cdot$ Number 12 - December 2008
Biologic Characteristics of Fibrous Hamartoma from Congenital Pseudarthrosis of the Tibia

\section{Alkaline Phosphatase Activity Assays}

Cells were plated at $3 \times 10^{4}$ cells per well into twenty-four-well plates and were grown in osteogenic media with 0 or $100 \mathrm{ng} / \mathrm{mL}$ rhBMP-2 (R and D Systems) for two weeks. Alkaline phosphatase activities were chemically determined as previously described $^{20}$. Ratios of the alkaline phosphatase activities of BMP-treated and nontreated cells were calculated.

\section{$R A W_{264.7}$ Coculture Study}

Cells from the $\mathrm{RAW}_{264.7}$ cell line (ATCC [American Type Culture Collection], Rockville, Maryland), a murine monocytemacrophage cell line known to differentiate into osteoclast-like cells after RANKL stimulation ${ }^{21}$, were plated at $1 \times 10^{3}$ cells per well into a ninety-six-well plate along with tibial periosteal or fibrous hamartoma cells at $1 \times 10^{3}$ cells per well, and cultured in $\alpha$-MEM containing $8 \%$ fetal bovine serum for five days. Then they were fixed with $1 \%$ paraformaldehyde, and tartrateresistant acid phosphatase (TRAP) histochemical staining was performed. TRAP-positive multinuclear cells with more than two nuclei were counted.

\section{Results}

\section{Fibrous Hamartoma Cells Maintained Mesenchymal} Lineage Phenotype

S pindle-shaped adherent cells were enzymatically dissoci$\mathcal{S}$ ated from fibrous hamartomas of patients with congenital pseudarthrosis of the tibia and from the distal tibial periosteum of patients with cerebral palsy. Fibrous hamartoma cells could not be differentiated from tibial periosteal cells on the basis of morphology. Cells from one tibial periosteal specimen and six fibrous hamartoma specimens were tested for immunophenotype. All of the cells expressed CD44 and CD105 but were negative for CD45 and CD14 (Figs. 1-A, 1-B, and $1-\mathrm{C})$. The mRNA expressions of BMP- 2 and BMP-4 and of their receptors were examined in cells from one tibial periosteal specimen and five fibrous hamartoma specimens by RTPCR. Although the assay was not quantitative, all of the cells tested strongly expressed the mRNAs of BMPs and their receptors. With regard to COL1A1, alkaline phosphatase, and osteocalcin mRNA expression, RNase protection assay showed that the tibial periosteal cells expressed the mRNAs of all of the three osteoblastic marker genes even without BMP treatment. COL1A1 and alkaline phosphatase mRNA were detected without BMP treatment in all of the fibrous hamartoma cells tested, but osteocalcin mRNA expression was detected only in cells from two fibrous hamartoma specimens (FH2 and FH3) (Figs. $2-\mathrm{A}$ and 2-B) (Table I). These findings indicate that fibrous hamartoma cells maintained some mesenchymal lineage phenotype but were at different stages of osteoblastic differentiation.

\section{BMP Treatment Did Not Enhance the Osteoblastic Differentiation of Fibrous Hamartoma Cells}

The finding that all tissues expressed the mRNAs of BMPs and of their receptors led us to investigate the response to exogenous BMP. Tibial periosteal cells showed a 4.9 -fold increase in alkaline phosphatase activity after two weeks of rhBMP-2 treatment. However, in all fibrous hamartoma cells tested, alkaline phosphatase activity reduced after rhBMP-2 treatment. The alkaline phosphatase activities of BMP-treated fibrous hamartoma cells ranged from $1.1 \%$ to $71.7 \%$ of those not treated with BMP (Figs. 3-A and 3-B).

BMP markedly increased the mRNA expressions of COL1A1, alkaline phosphatase, and osteocalcin in tibial periosteal cells, but showed a variable effect in fibrous hamartoma cells. BMP induced no change in these mRNA expressions in FH2 and FH4 cells (Table I). On the other hand, FH1 and FH3 cells (Table I) showed a marked decrease in the mRNA expressions of COL1A1 and alkaline phosphatase. FH3 cells, which expressed osteocalcin mRNA without BMP treatment, did not produce any detectable osteocalcin mRNA band after treatment with rhBMP-2 (Figs. 2-A and 2-B).

\section{Fibrous Hamartoma Cells Are Strongly Osteoclastogenic}

RANKL is a cytokine that promotes osteoclast differentiation when it binds to RANK, while OPG is a soluble decoy receptor that binds to RANKL, thereby inhibiting the effect of RANKL on osteoblasts and osteoclast precursors. The relative levels of RANKL and OPG mRNAs compared with that of GAPDH were estimated in cells from three tibial periosteal and four fibrous hamartoma specimens. The RANKL/GAPDH mRNA ratio was higher in cells from the four fibrous hamartoma specimens than in cells from the three tibial periosteal specimens. When the mean value of the three tibial periosteal specimens was set at 1.0 (range, 0.44 to 1.66 ), the values of the four fibrous hamartoma specimens ranged from 2.47 to 118.8 , with an average of 48.1. On the other hand, the OPG/GAPDH mRNA ratio was lower in fibrous hamartoma cells than in tibial periosteal cells. When the mean value of the three tibial periosteal specimens was set at 1.0 (range, 0.32 to 1.66 ), the values of the four fibrous hamartoma specimens ranged from 0.091 to 0.20 , with an average of 0.15 (Figs. 4 -A and 4-B).

We also tested the osteoclastogenic activity of fibrous hamartoma cells in a $\mathrm{RAW}_{264.7}$ cell coculture experiment. When $1 \times 10^{3} \mathrm{RAW}_{264.7}$ cells were cocultured with $1 \times 10^{3}$ cells from two tibial periosteal specimens, a mean (and standard deviation) of only $5.2 \pm 0.84$ (TP2) or $9.5 \pm 1.9$ (TP3) TRAPpositive, multinucleated cells was formed (Table I). However, when $\mathrm{RAW}_{264.7}$ cells were cocultured with cells from fibrous hamartoma specimens, the mean numbers of TRAP-positive, multinucleated cells per well were $34.4 \pm 26.0,45.6 \pm 12.0$, $57.2 \pm 24.7$, and $110.8 \pm 13.9$, respectively, revealing significantly higher osteoclastogenic activity than that with tibial periosteal cells ( $\mathrm{p}<0.01$, Mann-Whitney test) (Figs. 5-A and 5-B).

\section{Discussion}

Cibrous hamartoma is a fibromatosis-like lesion found at F pseudarthrosis sites, and is a key component of the pathology of congenital pseudarthrosis of the tibia ${ }^{1,3}$, which is believed to originate from aberrant periosteum growth. In the current study, we characterized the fibrous hamartoma cell phenotype, and found it to be CD44+/CD105+/CD45-/ CD14-, which is consistent with the immunophenotype of 
The Journal of Bone \& Joint Surgery - Jbjs.org Volume $90-\mathrm{A} \cdot$ Number 12 - December 2008
Biologic Characteristics of Fibrous Hamartoma from Congenital Pseudarthrosis of the Tibia mesenchymal lineage cells $s^{17,18}$. This immunophenotype was shared by tibial periosteal cells, which were presumed to represent normal control of fibrous hamartoma tissue. This study also showed expression of BMPs and their receptors in fibrous hamartoma cells. The diverse expression pattern of later stage osteoblastic marker genes in fibrous hamartoma cells treated with exogenous BMP (Figs. 2-A and 2-B) suggests that fibrous hamartoma tissue may be composed of cells of mesenchymal lineage at different stages of osteoblastic differentiation from case to case.

It is interesting to note that all tibial periosteal and fibrous hamartoma cells tested expressed the mRNAs of BMP-2, BMP-4, and of their receptors, indicating autocrine or paracrine BMP signals. However, the response of fibrous hamartoma cells to exogenous rhBMP-2 treatment was different from that of tibial periosteal cells. In all of the fibrous hamartoma cells tested, alkaline phosphatase activity was reduced by rhBMP-2. Moreover, rhBMP-2 did not change or even downregulated the mRNA expressions of osteoblastic marker genes in fibrous hamartoma cells. These findings suggest that fibrous hamartoma cells are arrested at a certain stage during osteoblastic differentiation. As endogenous BMPs and their receptors express in fibrous hamartoma cells, aberrant responses to BMP signaling may be due to perturbation of the intracellular signaling transduction pathway. All patients involved in the present study had the NF1 phenotype, which is caused by a heterozygous mutation in the $\mathrm{Nf1}$ gene encoding neurofibromin'. Nf1 haploinsufficient mice showed a lower number of mesenchymally originated cells with the osteoblastic phenotype $^{13}$ and premature apoptosis, higher proliferation, and attenuated differentiation of committed osteoprogeni$\operatorname{tors}^{14}$. Moreover, Schindeler et al. showed reduced efficacy of surgically implanted rhBMP- $2^{22}$. Therefore, the Nf1 \pm genotype could contribute to fibrous hamartoma development by blocking the osteoblastic differentiation of periosteal cells.

Because BMP has produced promising results in animal bone-healing models, and has proven clinical efficacy for the treatment of adult tibial nonunion and spinal fusion, several authors have investigated the effects of BMP in congenital pseudarthrosis of the tibia. However, the reported results are contradictory. In two case reports, successful osteosynthesis was achieved ${ }^{23,24}$, but in a case series of five patients with congenital pseudarthrosis of the tibia who were treated with rhBMP-7 and intramedullary rods or external fixation, unequivocal union was achieved only in one patient ${ }^{25}$. The in vitro data obtained during the present study suggest that BMP treatment may not induce fibrous hamartoma cells to differentiate to osteoblasts. Rather, BMP signaling may impair osteoblastic differentiation of fibrous hamartoma. However, exogenous BMP might affect the healthy osteoblastic lineage cells to differentiate into osteoblasts, contributing to healing of the pseudarthrosis.

Increased osteoclastic activity appears to be essential in the development and recurrence of pseudarthrosis. Several studies have been conducted on the effect of Ras signaling on osteoclastogenesis $^{15,16}$. Inhibiting Ras by dominant negative Ras overexpression rapidly induced the apoptosis of osteoclasts, whereas ERK activation by constitutively active MEK1 increased their survival ${ }^{15}$. Moreover, the inhibition of ERK phosphorylation by PD98059 (a MAPK/ERK kinase-1 inhibitor) caused a loss of ruffled border, apoptosis, and a loss of polarity in osteoclasts ${ }^{16}$. These findings support that $N f 1$ haploinsufficiency and subsequent Ras-MAPK overactivity in osteoclasts and their precursors should enhance osteoclastogenesis. The current study provides evidence that fibrous hamartoma cells positively affect osteoclasts and their precursors; the RANKL-to-OPG ratio was much higher in fibrous hamartoma cells than in distal tibial periosteal cells, and coculture with fibrous hamartoma cells significantly enhanced the osteoclastic differentiation of $\mathrm{RAW}_{264.7}$ cells. Therefore, in patients with neurofibromatosis type 1, fibrous hamartoma tissue appears to further activate osteoclasts and their precursors, which were already activated by Nf1 haploinsufficiency.

These findings suggest that inhibition of osteoclastic activity may be effective in the management of congenital pseudarthrosis of the tibia. Schindeler et al. ${ }^{22}$ showed that the addition of bisphosphonate improved deficient ectopic bone

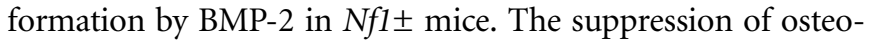
clasts is also expected to prevent fibrous hamartoma tissue from encroaching into tibial bone tissue and thus help osteosynthesis or prevent recurrence of fracture. However, little is known of the long-term safety of bisphosphonate in patients young enough to be growing, and thus the benefits and risks of this type of therapeutic intervention require careful investigation.

There are several limitations in this study. First, because of the rarity of congenital pseudarthrosis of the tibia and the difficulty in obtaining normal periosteum, the numbers of both control subjects and patients with congenital pseudarthrosis of the tibia were too small to allow statistical analysis and to draw any solid conclusion. Second, cells from primary tissue culture may not represent all of the cellular populations in fibrous hamartoma. Third, as these results are from in vitro experiments performed in environments totally different from that in the human body, the cells are not necessarily expected to behave as in experiments in vivo. Fourth, as specimens used in this study were harvested from patients with an established, atrophic type of congenital pseudarthrosis of the tibia associated with neurofibromatosis type 1 in a certain age range, fibrous hamartoma from other types of congenital pseudarthrosis of the tibia not associated with neurofibromatosis type 1 or in another age group may behave differently. Also, the current study cannot explain why congenital pseudarthrosis of the tibia develops preferably at the distal ends of the tibia and fibula. Despite these limitations, this study revealed that fibrous hamartoma in congenital pseudarthrosis of the tibia associated with neurofibromatosis type 1 consists of cells that maintain some mesenchymal lineage cell phenotypes, and the low osteogenicity and high osteoclastogenicity of these fibrous hamartoma cells can be the key pathogenic mechanism of congenital pseudarthrosis of the tibia. These findings need to 
The Journal of Bone \& JoINT Surgery $\cdot$ JBJS. Org Volume $90-\mathrm{A} \cdot$ Number $12 \cdot$ December 2008
Biologic Characteristics of Fibrous Hamartoma from

Congenital Pseudarthrosis of the Tibia be taken into consideration when planning the treatment of patients with congenital pseudarthrosis of the tibia.

Note: The authors thank Dong Yeon Lee, MD, and Jin A. Kim, MS (Seoul National University Children's Hospital), for their contribution in the experiments, and Sang-Han Lee, PhD, and JinSouth Korea), for providing the RAW 264.7 cell line and instruction on its handling.

Tae-Joon Cho, MD

Hye Ran Lee, MS

Won Joon Yoo, MD

In Ho Choi, MD

Department of Orthopaedic Surgery, Seoul National University Children's Hospital, 28 Yeongeon-dong Jongno-gu, Seoul 110-744, South Korea.
E-mail address for T.-J. Cho: tjcho@snu.ac.kr. E-mail address for H.R. Lee: lhranran@hanmail.net. E-mail address for W.J. Yoo: yoowj@snu.ac.kr. E-mail address for I.H. Choi: inhoc@snu.ac.kr

Joong-Bae Seo, MD

Department of Orthopaedic Surgery,

Dankook University Hospital, 16-5 Anseo-dong, Cheonan,

Chungnam 330-715, South Korea.

E-mail address: ssjb1990@dku.edu

Chin Youb Chung, MD

Department of Orthopaedic Surgery, Seoul National University Bundang Hospital, 300 Gumi-dong, Bundang-gu, Seongnam-si,

Gyeonggi-do 463-707, South Korea.

E-mail address: chin@snubh.org

\section{References}

1. Boyd HB. Pathology and natural history of congenital pseudarthrosis of the tibia. Clin Orthop Relat Res. 1982;166:5-13.

2. Kristiansen LP, Steen $\mathrm{H}$, Terjesen T. Residual challenges after healing of congenital pseudarthrosis in the tibia. Clin Orthop Relat Res. 2003;414:228-37.

3. Ippolito E, Corsi A, Grill F, Wientroub S, Bianco P. Pathology of bone lesions associated with congenital pseudarthrosis of the leg. J Pediatr Orthop B. 2000;9: 3-10.

4. Briner J, Yunis E. Ultrastructure of congenital pseudarthrosis of the tibia. Arch Pathol. 1973;95:97-9.

5. Mariaud-Schmidt RP, Rosales-Quintana S, Bitar E, Fajardo D, Chiapa-Robles G, Gonzalez-Mendoza A, Barros-Nunez P. Hamartoma involving the pseudarthrosis site in patients with neurofibromatosis type 1. Pediatr Dev Pathol. 2005;8: 190-6.

6. Hefti F, Bollini G, Dungl P, Fixsen J, Grill F, Ippolito E, Romanus B, Tudisco C, Wientroub S. Congenital pseudarthrosis of the tibia: history, etiology, classification, and epidemiologic data. J Pediatr Orthop B. 2000;9:11-5.

7. Hermanns-Sachweh B, Senderek J, Alfer J, Klosterhalfen B, Büttner R, Füzesi L, Weber M. Vascular changes in the periosteum of congenital pseudarthrosis of the tibia. Pathol Res Pract. 2005;201:305-12.

8. Crawford AH, Schorry EK. Neurofibromatosis update. J Pediatr Orthop. 2006;26:413-23.

9. Gutmann DH, Wood DL, Collins FS. Identification of the neurofibromatosis type 1 gene product. Proc Natl Acad Sci USA. 1991;88:9658-62.

10. Bollag G, Clapp DW, Shih S, Adler F, Zhang YY, Thompson P, Lange BJ, Freedman MH, McCormick F, Jacks T, Shannon K. Loss of NF1 results in activation of the Ras signaling pathway and leads to aberrant growth in haematopoietic cells. Nat Genet. 1996;12:144-8.

11. Kuorilehto T, Nissinen M, Koivunen J, Benson MD, Peltonen J. NF1 tumor suppressor protein and mRNA in skeletal tissues of developing and adult normal mouse and NF1-deficient embryos. J Bone Miner Res. 2004;19:983-9.

12. Kuorilehto $T$, Ekholm E, Nissinen M, Hietaniemi K, Hiltunen A, Paavolainen $P$, Penttinen R, Peltonen J. NF1 gene expression in mouse fracture healing and in experimental rat pseudarthrosis. J Histochem Cytochem. 2006;54:363-70.

13. Wu X, Estwick SA, Chen S, Yu M, Ming W, Nebesio TD, Li Y, Yuan J, Kapur R, Ingram D, Yoder MC, Yang FC. Neurofibromin plays a critical role in modulating osteoblast differentiation of mesenchymal stem/progenitor cells. Hum Mol Genet. 2006:15:2837-45
14. Yu X, Chen S, Potter OL, Murthy SM, Li J, Pulcini JM, Ohashi N, Winata T, Everett ET, Ingram D, Clapp WD, Hock JM. Neurofibromin and its inactivation of Ras are prerequisites for osteoblast functioning. Bone. 2005;36:793-802.

15. Miyazaki $T$, Katagiri $H$, Kanegae $Y$, Takayanagi $H$, Sawada $Y$, Yamamoto $A$, Pando MP, Asano T, Verma IM, Oda H, Nakamura K, Tanaka S. Reciprocal role of ERK and NF-kappaB pathways in survival and activation of osteoclasts. J Cell Biol. 2000;148:333-42.

16. Nakamura $\mathrm{H}$, Hirata A, Tsuji T, Yamamoto $T$. Role of osteoclast extracellular signal-regulated kinase (ERK) in cell survival and maintenance of cell polarity. J Bone Miner Res. 2003;18:1198-205.

17. Kolf CM, Cho E, Tuan RS. Mesenchymal stromal cells. Biology of adult mesenchymal stem cells: regulation of niche, self-renewal and differentiation. Arthritis Res Ther. 2007;9:204.

18. Suva D, Garavaglia G, Menetrey J, Chapuis B, Hoffmeyer P, Bernheim L, Kindler V. Non-hematopoietic human bone marrow contains long-lasting, pluripotential mesenchymal stem cells. J Cell Physiol. 2004:198:110-8.

19. Cho TJ, Gerstenfeld LC, Einhorn TA. Differential temporal expression of members of the transforming growth factor-beta superfamily during murine fracture healing. J Bone Miner Res. 2002;17:513-20.

20. Donahue HJ, Li Z, Zhou Z, Yellowley CE. Differentiation of human fetal osteoblastic cells and gap junctional intercellular communication. Am J Physiol Cell Physiol. 2000;278:C315-22.

21. García Palacios V, Robinson LJ, Borysenko CW, Lehmann T, Kalla SE, Blair HC. Negative regulation of RANKL-induced osteoclastic differentiation in RAW264.7 cells by estrogen and phytoestrogens. J Biol Chem. 2005:280:13720-7.

22. Schindeler A, Ramachandran M, Godfrey $C$, Morse A, McDonald M, Mikulec $K$, Little DG. Modeling bone morphogenetic protein and bisphosphonate combination therapy in wild-type and Nf1 haploinsufficient mice. J Orthop Res. 2008;26:65-74.

23. Fabeck L, Ghafil D, Gerroudj M, Baillon R, Delincé P. Bone morphogenetic protein 7 in the treatment of congenital pseudarthrosis of the tibia. J Bone Joint Surg Br. 2006;88:116-8.

24. Anticevic D, Jelic M, Vukicevic S. Treatment of a congenital pseudarthrosis of the tibia by osteogenic protein-1 (bone morphogenetic protein-7): a case report. J Pediatr Orthop B. 2006;15:220-1.

25. Lee FY, Sinicropi SM, Lee FS, Vitale MG, Roye DP Jr, Choi IH. Treatment of congenital pseudarthrosis of the tibia with recombinant human bone morphogenetic protein-7 (rhBMP-7). A report of five cases. J Bone Joint Surg Am.

$2006 ; 88: 627-33$ 